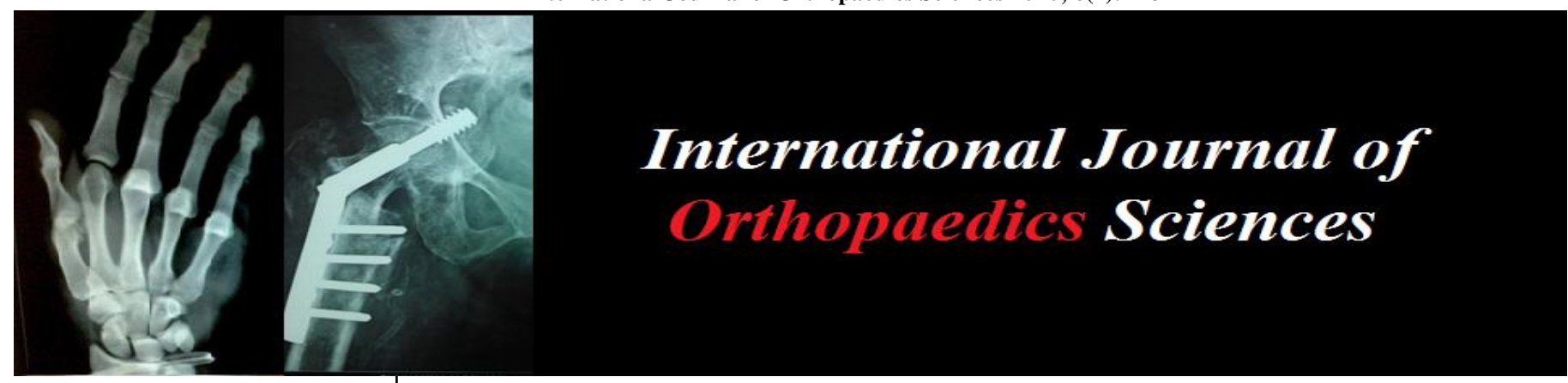

E-ISSN: 2395-1958

P-ISSN: 2706-6630

IJOS 2020; 6(2): 243-247

(C) 2020 IJOS

www.orthopaper.com

Received: 20-02-2020

Accepted: 22-03-2020

Roger Kennedy X

Junior Resident, Department of

Orthopaedics, Sri Devaraj Urs

Medical College, Sduaher, Kolar,

Karnataka, India

Arun HS

Professor and Head of,

Department of Orthopaedics, Sri

Devaraj Urs Medical College,

Sduaher, Kolar, Karnataka,

India

\section{A prospective study on role of hydraulic distension along with steroid under local anaesthesia in the management of frozen shoulder}

\author{
Roger Kennedy X and Arun HS
}

DOI: https://doi.org/10.22271/ortho.2020.v6.i2d.2046

\section{Abstract}

Introduction: Frozen shoulder" is a chronic condition characterized by gradually progressive, painful restriction of all shoulder joint movement, with slow spontaneous recovery of either partial or complete movement over a period of time. Although many treatment options have been proposed for the frozen shoulder syndrome, each has limitations. Hydro dilation technique was developed in order to loosen the reported contraction and adhesion. we evaluated the Range of movement and pain relief of shoulder following "Hydraulic distension under local anaesthesia along with a steroid" pre and post distension.

Material and methods: A prospective observational study was conducted in the department of orthopaedics at RLJ hospital attached to Sri Devaraj Urs Medical College between June 2018 to November 2019 for a period of 1.5 year. All the Patients with Peri arthritis shoulder and age above 30 years were included in the study. After obtaining the informed consent from the patients, Demographic data, History, Clinical Examination and details of investigations were recorded in study proforma. The pain and functional scoring used as per "The society of American Shoulder and elbow surgeons" and follow-up was done at 3 weeks, 6 weeks and 12 weeks after procedure. IBM SPSS version 22 was used for statistical analysis.

Results: Total 50 patients were included in the study. The average age of the study population was 52.68 \pm 9.79. There were no patients with complete disability. Marked pain (grade 1) was observed on presentation in $46(92 \%)$ of the subjects. Post distension only $9(18 \%)$ had pain. Flexion, abduction, internal rotation, external rotation movements of the shoulder have improved post distention and were statistically significant at $3^{\text {rd }}, 6^{\text {th }}, 12$ th week. The mean ASES was $36.04 \pm 5.84$ at base line, it was 67.6 \pm 7.64 at $6^{\text {th }}$ week and $91.04 \pm 8.68$ at $12^{\text {th }}$ week. The differences in the ASES score at $6^{\text {th }}$ week and $12^{\text {th }}$ week follow up period with baseline value were statistically significant (P value <0.001).

Conclusion: Hydraulic distension is a safe, reliable, cost effective modality in treating the chronically distressing painful condition of frozen shoulder.

Keywords: Hydraulic distension, local anaesthesia, frozen shoulder

\section{Introduction}

"Frozen shoulder" is a chronic condition characterized by gradually progressive, painful restriction of all shoulder joint movement, with slow spontaneous recovery of either partial or complete movement over a period of time ${ }^{[1]}$. The first recorded description of a frozen shoulder was reported by Duplay in 1872 in his description of a "periarthritis scapulohumeral" and the word 'frozen shoulder' was first coined by Codman in $1934^{[2]}$. He described the symptoms to be slow onset of pain felt near the insertion of the deltoid muscle, inability to sleep on the afflicted side, and limited active and passive elevation and external rotation, yet with a normal radiological appearance.

The best techniques of conservative management of adhesive capsulitis has included combinations of regimens that include physiotherapy utilising a number of techniques, hydraulic distension of the glenohumeral joint and intra-articular steroid injections. While in operative management point of view, Arthroscopic capsular release had immediate recovery of function and earlier return to work.

Although variety of treatment options have been reported for the frozen shoulder syndrome, each has its disadvantages. Improvement with Home exercises may not alter the rate of natural
Corresponding Author:

Arun HS

Professor and Head of,

Department of Orthopaedics,

Sri Devaraj Urs Medical

College, Sduaher, Kolar,

Karnataka, India 
recovery. Significant complications have been documented with Manipulation under anesthesia but significant and publications report protracted recovery ${ }^{[3]}$. Poor outcomes by few patients were reported with Arthroscopic release done under general anesthesia as it is a invasive procedure ${ }^{[4]}$. An infrequently cited option is hydraulic joint capsule distension under local anesthesia (hydroplasty) ${ }^{[5]}$. It is also called as Distension arthrography (also known as hydrodilatation). The hydrodilatation procedure was first described by Andrèn and Lundberg. This technique was developed in order to loosen the reported contraction and adhesion. It is based on the principle of injection into the glenohumeral joint under pressure. Fareed and Gallivan ${ }^{[6]}$, initially reported in a case series of twenty patients that this is an office technique without arthrography, and the patients in this study noted immediate pain resolution, return of normal function and normal sleep.

However, despite the ubiquity of this condition and the advances in shoulder surgery over the last fourteen decades there are still many unknowns in deciding what the best treatment options are for this disease condition. In this study we evaluated the Range of movement and pain relief of shoulder following "Hydraulic distension under local anaesthesia" pre and post distension.

\section{Material and methods}

A prospective observational study was conducted in the department of orthopaedics at RLJ hospital attached to Sri Devaraj Urs Medical College between June 2018 to November 2019 for a period of 1.5 year. All the Patients with Peri arthritis shoulder and age above 30 years were included in the study. After obtaining the informed consent from the patients who agree to be part of study. Demographic data, History, Clinical Examination and details of investigations were recorded in study proforma, and then were taken for procedure. All the patients were got intraarticular Hydraulic distension with Normal saline. The surgeon had injected a single dose of $30-40 \mathrm{ml}$ of the Normal saline or upto the ease of resistance felt during infiltration, along with steroid into the intraarticular area of the shoulder in an aseptic technique. Posterior Approach was used. $2 \mathrm{~cm}$ below the angle of the acromion and $2 \mathrm{~cm}$ medial to it (Mike walton). The needle is directed anteriorly and medially towards the coracoid process. 2 to $3 \mathrm{~cm}$ depth was reached with a 20 gauge needle. Mean joint depth would be $43.5 \mathrm{~mm}$ at posterior and $27.1 \mathrm{~mm}$ at anterior side. $X$ rays, Ultrasound was done if necessary in doubtful cases of extravasation of fluid into the pericapsular area. Pendulum and range of movement exercise at home are advised for all the patients. Findings were recorded and outcomes were measured before the injection and during each follow-up at 3 weeks, 6 weeks and 12 weeks after procedure. The pain and functional scoring used as per "The society of American Shoulder and elbow surgeons". Before and after the intervention was assessed one way repeated measures ANOVA. $\mathrm{P}$ value $<0.05$ was considered statistically significant. IBM SPSS version 22 was used for statistical analysis $^{[7]}$.

\section{Results}

The mean age was $52.68 \pm 9.79$ in the study population, ranged between 30 years to 80 years $(95 \%$ CI 49.90 to 55.46). Among the study population, 36 (72\%) were participants male and remaining $14(28 \%)$ participants were female. Among the study population, $23(46 \%)$ participants had dominant. Among the study population, 22 (44\%) participants had diabetes, $8(16 \%)$ participants had hypertension and only 1 (2\%) participant had IHD.

Table 1: Descriptive analysis of age age group gender side Comorbidities in study population $(\mathrm{N}=50)$

\begin{tabular}{|c|c|}
\hline Parameter & Frequency \\
\hline Age & $52.68 \pm 9.79$ \\
\hline \multicolumn{2}{|c|}{ Age Group } \\
\hline 30 to 39 & $3(6.00 \%)$ \\
\hline 40 to 49 & $18(36.00 \%)$ \\
\hline 50 to 59 & $15(30.00 \%$ \\
\hline 60 to 69 & $12(24.00 \%)$ \\
\hline$\geq 70$ & $2(2.00 \%)$ \\
\hline \multicolumn{2}{|c|}{ Gender } \\
\hline Male & $36(72.0 \%)$ \\
\hline \multicolumn{2}{|c|}{ Side } \\
\hline Dominant & $14(28.0 \%$ \\
\hline Not dominant & $23(46.0 \%)$ \\
\hline DM & $27(54.0 \%)$ \\
\hline HTN & $22(44.0 \%)$ \\
\hline IHD & $1(16.0 \%)$ \\
\hline Nil & $19(38.0 \%)$ \\
\hline
\end{tabular}

Table 2: Comparison of mean flexion abduction internal rotation external rotation on the time of presentation and follow up time periods $(\mathrm{N}=50)$

\begin{tabular}{|c|c|c|}
\hline Follow up time periods & Mean \pm SD & P value \\
\hline \multicolumn{3}{|c|}{ Flexion } \\
\hline On the time of presentation & $70.2 \pm 23.6$ & \multirow{5}{*}{$<0.001$} \\
\hline Immediately post distension & $99.1 \pm 25.83$ & \\
\hline at $3^{\text {rd }}$ week & $120.8 \pm 23.81$ & \\
\hline at $6^{\text {th }}$ week & $140.98 \pm 24.16$ & \\
\hline at $12^{\text {th }}$ week & $153.9 \pm 21.48$ & \\
\hline \multicolumn{3}{|c|}{ Abduction } \\
\hline On the time of presentation & $71.7 \pm 27.91$ & \multirow{5}{*}{$<0.001$} \\
\hline Immediately post distension & $103.4 \pm 25.28$ & \\
\hline at $3^{\text {rd }}$ week & $130 \pm 26.86$ & \\
\hline at $6^{\text {th }}$ week & $145.4 \pm 24.41$ & \\
\hline at $12^{\text {th }}$ week & $155.1 \pm 22.05$ & \\
\hline \multicolumn{3}{|c|}{ Internal Rotation } \\
\hline On the time of presentation & $28.3 \pm 10.58$ & \multirow{5}{*}{$<0.001$} \\
\hline Immediately post distension & $47.5 \pm 12.13$ & \\
\hline at $3^{\text {rd }}$ week & $62.1 \pm 15.81$ & \\
\hline at $6^{\text {th }}$ week & $72.3 \pm 15.16$ & \\
\hline at $12^{\text {th }}$ week & $79.3 \pm 13.05$ & \\
\hline \multicolumn{3}{|c|}{ External Rotation } \\
\hline On the time of presentation & $21.7 \pm 5.77$ & \multirow{5}{*}{$<0.001$} \\
\hline Immediately post distension & $31.4 \pm 5.63$ & \\
\hline at $3^{\text {rd }}$ week & $39.1 \pm 6.6$ & \\
\hline at $6^{\text {th }}$ week & $46.4 \pm 5.81$ & \\
\hline at $12^{\text {th }}$ week & $52.8 \pm 6.16$ & \\
\hline
\end{tabular}

The mean flexion on the time of presentation was $70.2 \pm 23.6$, it was $99.1 \pm 25.83$ at immediately post distension, it was $120.8 \pm 23.81$ at $3^{\text {rd }}$ week, it was $140.98 \pm 24.16$ at $6^{\text {th }}$ week and it was $153.9 \pm 21.48$ at $12^{\text {th }}$ week. The difference in flexion at different follow up periods was statistically significant. ( $\mathrm{P}$ value $<0.001$ ). The mean Abduction on the time of presentation was $71.7 \pm 27.91$, it was $103.4 \pm 25.28$ at immediately post distension, it was $130 \pm 26.86$ at $3^{\text {rd }}$ week, it was $145.4 \pm 24.41$ at $6^{\text {th }}$ week and it was $155.1 \pm 22.05$ at $12^{\text {th }}$ week. The difference in Abduction at different follow up periods was statistically significant. ( $\mathrm{P}$ value $<0.001)$. The mean internal rotation on the time of presentation was $28.3 \pm$ 10.58 , it was $47.5 \pm 12.13$ at immediately post distension, it 
was $62.1 \pm 15.81$ at $3^{\text {rd }}$ week, it was $72.3 \pm 15.16$ at $6^{\text {th }}$ week and it was $79.3 \pm 13.05$ at $12^{\text {th }}$ week. The difference in internal rotation at different follow up periods was statistically significant. ( $\mathrm{P}$ value $<0.001$ ). The mean external rotation on the time of presentation was $21.7 \pm 5.77$, it was $31.4 \pm 5.63$ at immediately post distension, it was $39.1 \pm$ 6.6 at $3^{\text {rd }}$ week, it was $46.4 \pm 5.81$ at $6^{\text {th }}$ week and it was 52.8 \pm 6.16 at $12^{\text {th }}$ week. The difference in external rotation at different follow up periods was statistically significant. ( $\mathrm{P}$ value $<0.001)$.

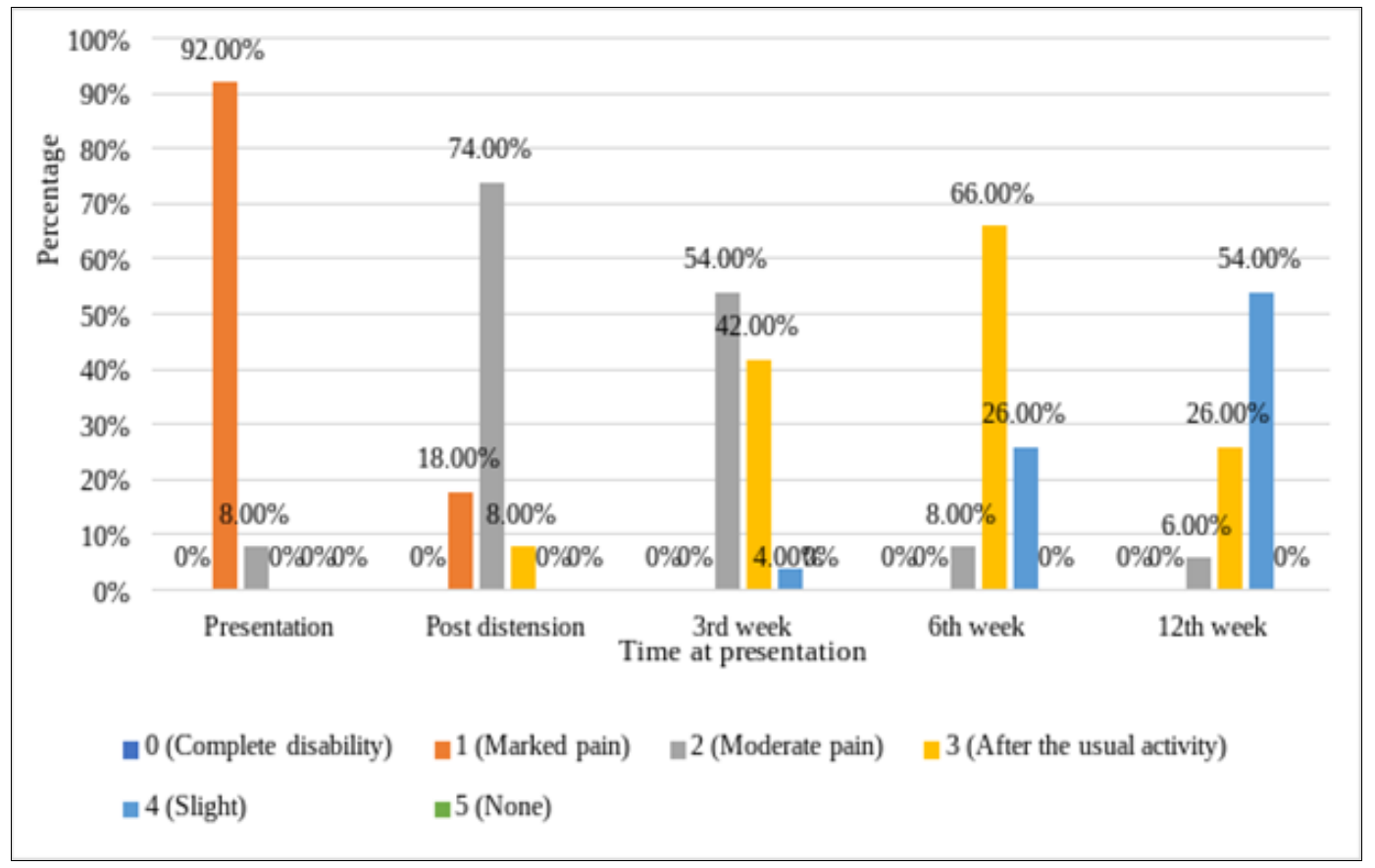

Fig 1: Clustered bar chart of pain score in the study population $(\mathrm{N}=50)$

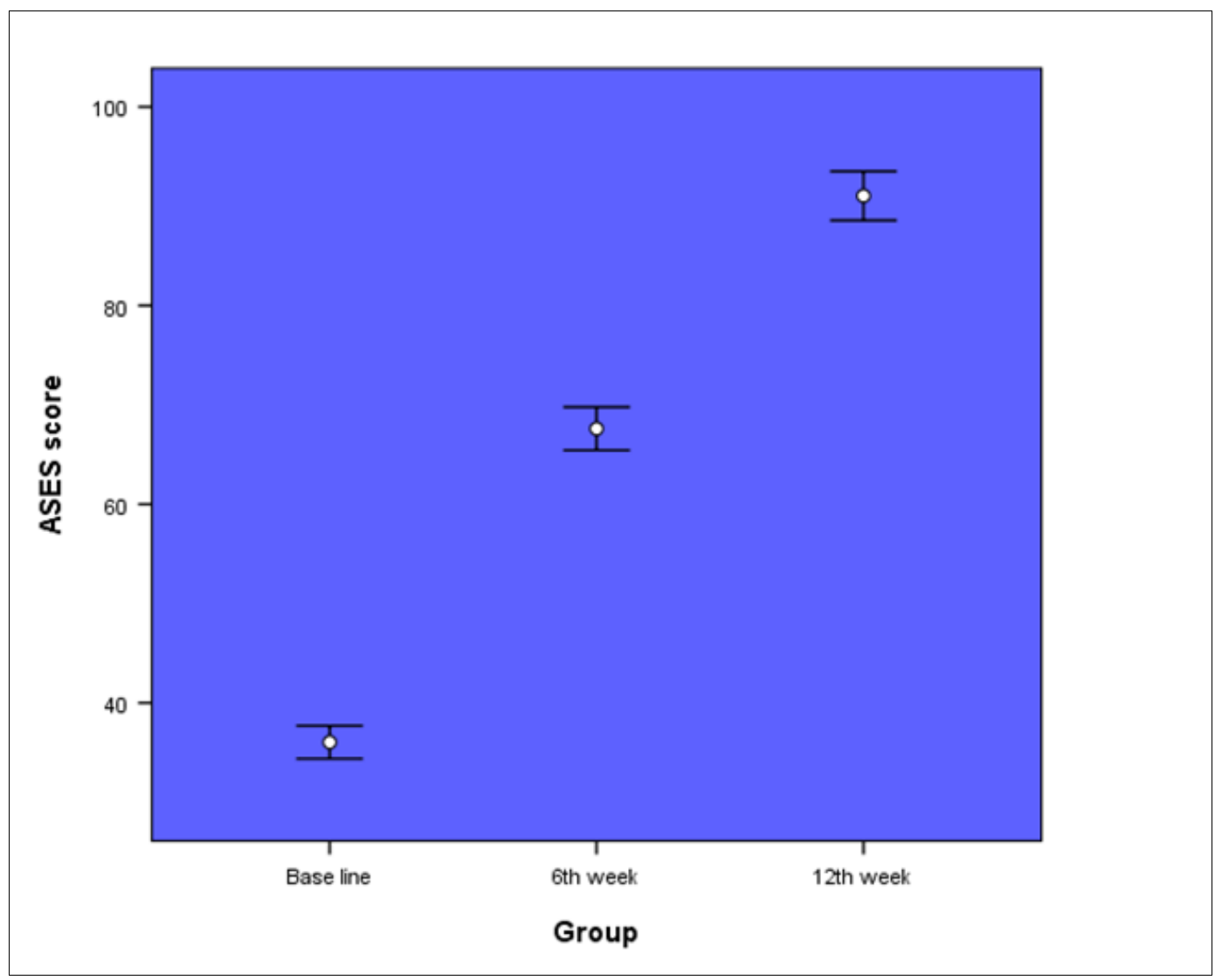

Fig 2: Error bar chart of comparison of mean ASES score across the different time periods $(\mathrm{N}=50)$

\section{Discussion}

Adhesive capsulitis is an extremely disabling disorder, characterized with pain and remitting shoulder stiffness and pain. Clinically it has symptoms of severe pain and insidious shoulder stiffness, which results in limited passive and active external rotation and forward flexion. Recently arthroscopic treatment has also been recommended for this condition. It involves the intra- articular injection of a large amount of normal saline to distend and rupture the capsular adhesions. In this study we evaluated the Range of movement and pain 
relief of shoulder following "Hydraulic distension under local anaesthesia along with a steroid" pre and post distension.

Total 50 patients were included in the study and were evaluated post operatively followed by 3 weeks, 6 weeks and 12 weeks after procedure. The average age of the study population was $52.68 \pm 9.79$, ranging between 30 years to 80 years (95\% CI 49.90 to 55.46). It is almost similar to the study conducted by Buchbinder et al. ${ }^{[8]}$ who reported a slightly higher average age of 57.2 years in their study. In the present study $36(72 \%)$ participants were males and $14(28 \%)$ participants were females. Age and sex distribution reported in the literature have been widely variable, according to Segmuller et al. ${ }^{[9]}$ ages ranging from 22 years to 85 years were reported. In a study by shah et al. ${ }^{[10]}$ reported that with percentage of female subjects ranged from $48 \%$ to $84 \%$ which is contradicting our study because of the different socio demographic characteristics of the area.

Majority of the participants $18(36 \%)$ were in 40 to 49 years age group followed by $15(30 \%)$ in 50 to 59 years age group, $12(24 \%)$ in 60 to 69 years age group, $3(6 \%)$ in 30 to 39 years age group, 2(4\%) were greater than 70 years. Among the study population, 23 (46\%) participants had dominant side involved. In a study conducted by Mishra et al. ${ }^{[11]} 8$ patients $((10 \%)$ had bilateral involvement while in 33 patients $(41 \%)$ had involvement of the dominant side that is right shoulder, while 39 patients (49\%) were found to have left shoulder involvement.

Few patients were found to have certain associated conditions like $22(44 \%)$ participants had diabetes, $8(16 \%)$ participants had hypertension and only 1 (2\%) participant had IHD in our study. Similarly Mishra et al. ${ }^{[11]}$ in their study had 12 patients had diabetes mellitus, 10 patients had hypertension, 13 patients had osteoarthritis of knee, 1 patient diagnosed with peptic ulcer, and 3 patients of bronchial asthma were seen.

In the current study, The mean flexion on the time of presentation was $70.2 \pm 23.6$, it was $99.1 \pm 25.83$ at immediately post distension, it got further improved from the average of $120.8 \pm 23.81$ at $3^{\text {rd }}$ week, to $140.98 \pm 24.16$ at $6^{\text {th }}$ week and $153.9 \pm 21.48$ at $12^{\text {th }}$ week. The difference in flexion at different follow up periods was statistically significant. (P value $<0.001$ ). In a study done by Vad et al. ${ }^{[12]}$ range of flexion improved from a predistention mean of $92^{\circ}$ to a postdistention mean of $110^{\circ}$ and to $111^{\circ}$ at 1 year after distention. Accoding to Baums et al. ${ }^{[13]}$ mean flexion showed an improvement to $150^{\circ}$ (6 weeks) and respectively $160^{\circ}$ (36 months) compared to $85^{\circ}$ pre operatively.

The mean Abduction on the time of presentation in the present study was $71.7 \pm 27.91$, it got better by $103.4 \pm 25.28$ immediately post distension, further improved by $130 \pm 26.86$ at $3^{\text {rd }}$ week, $145.4 \pm 24.41$ at $6^{\text {th }}$ week and it $155.1 \pm 22.05$ at $12^{\text {th }}$ week. The difference in Abduction at different follow up periods was statistically significant. ( $\mathrm{P}$ value $<0.001$ ). In a study done by Vad et al. ${ }^{[12]}$ range of abduction improved from a predistention mean of $83^{\circ}$ to a postdistention mean of $107.1^{\circ}$ and to $106.8^{\circ}$ at 1 year postdistention. Baums et al. ${ }^{[13]}$ abduction improved from a mean of $70^{\circ}$ preoperatively to a mean of $140^{\circ}$ (6 weeks) and respectively $150^{\circ}$ at latest follow-up (36 months).

In the current study the mean internal rotation on the time of presentation was $28.3 \pm 10.58$, it was $47.5 \pm 12.13$ immediately post distension, it was $62.1 \pm 15.81$ at $3^{\text {rd }}$ week, it was $72.3 \pm 15.16$ at $6^{\text {th }}$ week and it was $79.3 \pm 13.05$ at $12^{\text {th }}$ week. The difference in internal rotation at different follow up periods was statistically significant. ( $\mathrm{P}$ value $<0.001)$. According to Baums et al. ${ }^{[13]}$ IR shows an improvement to a mean of $50^{\circ}$ (6 weeks) and of $60^{\circ}$ in the final examination. The mean external rotation on the time of presentation was $21.7 \pm 5.77$, it was $31.4 \pm 5.63$ at immediately post distension, it was $39.1 \pm 6.6$ at $3^{\text {rd }}$ week, it was $46.4 \pm 5.81$ at $6^{\text {th }}$ week and it was $52.8 \pm 6.16$ at $12^{\text {th }}$ week. The difference in external rotation at different follow up periods was statistically significant. (P value <0.001). Baums et al. ${ }^{[13]}$ Average ER in adduction improved from $10^{\circ}$ preoperatively to $45^{\circ}$ ( 6 weeks) and respectively $65^{\circ}$ in the latest follow-up assessment.

In a study conducted by Mao et al. ${ }^{[14]}$ on 12 patients flexion, Abduction, Internal rotation, External rotation among acute cases pre operatively was $111 \pm 10,101 \pm 18,64 \pm 12,24 \pm 8$ respectively. Post operatively it was $153 \pm 11,143 \pm 12,83 \pm$ 7, $69 \pm 15$ respectively. The difference in ROM pre and post operatively was statistically significant. ( $\mathrm{P}$ value $<0.001$ ). Flexion, Abduction, Internal rotation, External rotation among chronic cases pre operatively was $113 \pm 20,103 \pm 25,60 \pm 8$, $29 \pm 11$ respectively. Post operatively it was $148 \pm 16,149 \pm$ $13,86 \pm 9,63 \pm 13$ respectively. The difference in ROM pre and post operatively was statistically significant. ( $\mathrm{P}$ value $<0.001)$.

\section{Conclusion}

Hydraulic distension is a cost effective, safe, reliable, modality in treating the painful, chronically distressing adhesive capsulitis. This treatment can be practiced as an outpatient therapy, without any specialized equipments. It has absolutely no side effects, when performed with a right technique under aseptic precautions. Hence, we conclude that hydraulic distension under local anesthesia with steroid can be considered as a first line management option in patients with frozen shoulder.

\section{References}

1. Jacobs LG, Barton MA, Wallace WA, Ferrousis J, Dunn NA, Bossingham DH. Intra-articular distension and steroids in the management of capsulitis of the shoulder. BMJ. 1991; 302(6791):1498-501.

2. Uppal HS, Evans JP, Smith C. Frozen shoulder: A systematic review of therapeutic options. World J Orthop. 2015; 6(2):263-8.

3. Jacobs LG, Smith MG, Khan SA, Smith K, Joshi M. Manipulation or intra-articular steroids in the management of adhesive capsulitis of the shoulder? A prospective randomized trial. J Shoulder Elbow Surg. 2009; 18(3):348-53.

4. Manske RC, Prohaska D. Clinical commentary and literature review: diagnosis, conservative and surgical management of adhesive capsulitis. Shoulder Elbow. 2010; 2(4):238-54

5. van der Windt DAWM, Koes BW, Devillé W, Boeke AJP, de Jong BA, Bouter LM. Effectiveness of corticosteroid injections versus physio therapy for treatment of painful stiff shoulder in primary care: randomised trial. BMJ. 1998; 317:1292-6.

6. Fareed DO, Gallivan WR, Jr. Office management of frozen shoulder syndrome. Treatment with hydraulic distension under local anesthesia. Clin Orthop Relat Res. 1989(242):177-83.

7. IBM Corp. Released 2013. IBM SPSS Statistics for Windows, Version 22.0. Armonk, NY: IBM Corp.

8. Buchbinder R, Green S, Forbes A, Hall S, Lawler G. Arthrographic joint distension with saline and steroid improves function and reduces pain in patients with painful stiff shoulder: results of a randomised, double 
blind, placebo controlled trial. Ann Rheum Dis. 2004; 63(3):302-9.

9. Segmüller HE, Taylor DE, Hogan CS, Saies AD, Hayes MG. Arthroscopic treatment of adhesive capsulitis. J Shoulder Elbow Surg. 1995; 4(6):403-8.

10. Shah MA, Khan I. Comparison Between Manipulation under Anesthesia and Hydraulic Distension for Treatment of Frozen Shoulder. Ann King Edward Med Univ. 2008; 14(1):26.

11. Mishra AN, Mishra S, Dhungana HN. A study of clinical evaluation of effectiveness of hydraulic distension of shoulder in the management of frozen shoulder. Int $\mathbf{J}$ Orthod. 2017; 3(2):675-7.

12. Vad VB, Sakalkale D, Warren RF. The role of capsular distention in adhesive capsulitis. Arch Phys Med Rehabil. 2003; 84(9):1290-2.

13. Baums MH, Spahn G, Nozaki M, Steckel H, Schultz W, Klinger HM. Functional outcome and general health status in patients after arthroscopic release in adhesive capsulitis. Knee Surg Sports Traumatol Arthrosc. 2007; 15(5):638-44.

14. Mao CY, Jaw WC, Cheng HC. Frozen shoulder: correlation between the response to physical therapy and follow-up shoulder arthrography. Arch Phys Med Rehabil. 1997; 78(8):857-9. 